\title{
Planejamento familiar: significado para mulheres em idade reprodutiva
}

\author{
Family planning: significance for women of reproductive age
}

Raimunda Magalhães da Silva ${ }^{1}$

Kelly Nóbrega Cavalcante de Araújo ${ }^{1}$

Lya Araújo Costa Bastos ${ }^{1}$

Escolástica Rejane Ferreira Moura ${ }^{2}$

${ }^{1}$ Centro de Ciências da Saúde, Universidade de Fortaleza. Av. Washington Soares 1321, Edson Queiroz. 60811-905

Fortaleza CE.

rmsilva@unifor.br

2 Faculdade de Farmácia,

Odontologia e Enfermagem,

Universidade Federal do

Ceará.

\begin{abstract}
The study sought to comprehend the significance of family planning from the standpoint of women of reproductive age and identify their perceptions about the care received and the partner's participation in the decisions about the use of contraceptive methods. It is a descriptive study using a qualitative approach, conducted with 24 women who participated in the Family Planning program in a Basic Family Health Unit in Fortaleza, State of Ceará, Brazil, between August and October 2007. The information gleaned from interviews was recorded, organized into themes and analyzed on the basis of the concept of significance of symbolic interactionism. The results revealed three significant themes: the significance of family planning from the viewpoint of women of fertile age; interactions of women of fertile age in a family planning service; and male participation in family planning in terms of female significance. It was revealed that the significance of family planning for these women is related to avoiding pregnancy and according to values pertaining to their cultural, economic and social reality. The care is received in an isolated manner, without prioritizing women's needs and without input of an educational or empowerment stamp.
\end{abstract}

Key words Woman, Family planning, Significance, Symbolic interactionism
Resumo O estudo teve como objetivo compreender o significado do planejamento familiar dado por mulheres em idade reprodutiva, identificar suas percepções sobre a assistência recebida e a participação do parceiro nas decisões do uso do método anticoncepcional. Trata-se de um estudo descritivo, com abordagem qualitativa, desenvolvido com 24 mulheres que participavam do Programa de Planejamento Familiar (PF) em uma Unidade Básica de Saúde da Família de Fortaleza (Ceará), no período de agosto a outubro de 2007. As informações contidas nas entrevistas foram gravadas, organizadas em temáticas e analisadas com base no conceito de significado do interacionismo simbólico. Os resultados evidenciaram três temáticas significativas: o significado de planejamento familiar dado por mulheres em idade fértil; interações de mulheres em idade fértil em um serviço de planejamento familiar; e participação masculina no planejamento familiar conforme significado feminino. Constatou-se que o significado de planejamento familiar para essas mulheres está relacionado a evitar filhos e com valores pertinentes às suas realidades cultural, econômica e social. A assistência é recebida de forma isolada, não priorizando as necessidades da mulher, sem cunho educativo e emancipatório.

Palavras-chave Mulher, Planejamento familiar, Significado, Interacionismo simbólico 


\section{Introdução}

Até o final dos anos 70, as lutas em prol da saúde reprodutiva encontraram fortes barreiras, destacando-se o Estado autoritário, que não atendia às necessidades básicas da maioria da população; a hegemonia biomédica na elaboração de representações sobre o corpo feminino; o limitado lugar social ocupado pela mulher; e os programas verticais de planejamento familiar (PF), implementados por organismos internacionais desde a década de $60^{1}$. Estas mesmas autoras enfatizam que, por inúmeras vezes, as feministas enfrentaram a ordem médica e os "planejadores familiares" numa relação conflituosa, quando das reivindicações de seus direitos sexuais e reprodutivos. Os conflitos se davam exatamente porque os organismos internacionais visavam ao controle de natalidade, com pouca ou nenhuma decisão feminina, conduzindo-se pelo pensamento de que quanto maior o número de nascimentos, maior a miséria.

Somente na década de 80 , com a transição democrática vivida no país, caracterizada pela organização de movimentos sociais, as mulheres passaram a conquistar certos direitos relacionados às suas escolhas no campo do $\mathrm{PF}^{2}$. Tais conquistas deveram-se à democratização da educação para a saúde e a outras medidas que iam além da esfera biomédica, abrangendo a perspectiva da promoção da saúde e da participação dos indivíduos na corresponsabilidade pelo seu processo de saúde-doença.

Informações sobre saúde reprodutiva foram amplamente disseminadas, particularmente a partir do Programa de Assistência Integral à Saúde da Mulher (PAISM), lançado nacionalmente em 1983, adotando a política de ampliar o acesso da população aos meios de contracepção, todavia com informação e livre escolha.

Esses aspectos estão garantidos na Constituição Federal e na Lei n ${ }^{\circ} 9.263$, de 12 de janeiro de 1996, que trata do planejamento familiar, definindo como responsabilidade do Estado proporcionar condições para que homens e mulheres tenham acesso a informações, meios, métodos e técnicas para a regulação da sua fecundidade ${ }^{3}$.

Tal conquista se mantém na atual Política Nacional de Atenção Integral à Saúde da Mulher (PNAISM) como ação para reduzir a mortalidade materna e perinatal por causas preveníveis e evitáveis, além de fomentar a implementação de ações que contribuam para a garantia dos direitos humanos das mulheres ${ }^{4}$. Portanto, pode-se afirmar que, em termos de políticas públicas, o
Ministério da Saúde do Brasil apresenta uma proposta avançada de PF.

Atualmente, a assistência ao planejamento familiar no país é oferecida predominantemente pelas equipes do Programa Saúde da Família (PSF), com implantação iniciada em 1994. O PSF é desenvolvido por uma equipe multiprofissional, com a proposta de se estabelecer uma vinculação dos profissionais com a comunidade e de valorização e incentivo à participação comunitária.

Apesar do exposto, a assistência ao PF tem passado por descontinuidade ao longo dos anos, negando o que há de mais fundamental, que é a promoção da saúde sexual e reprodutiva de homens, mulheres e/ou casais, levando-se em conta aspectos culturais e socioeconômicos ${ }^{5}$. Por sua vez, a variedade de métodos anticoncepcionais (MAC) é limitada e sua provisão é irregular, percebendo-se, pois, uma distância entre o que está proposto como política e o que é realizado na prática $^{6}$.

Na perspectiva de que os serviços de PF ainda precisam ampliar o diálogo e a participação de seus usuários, como pessoas capazes de interagir e agir na realização de suas próprias escolhas, nos propomos a compreender o dito de mulheres sobre o planejamento familiar, numa análise embasada no interacionismo simbólico. Nessa concepção, a mulher é capaz de articular ideias, agrupar e reagrupar informações e exercer diferentes papéis na busca de atos benéficos para si e para a família. A capacidade de refletir, simbolizar, criar e comunicar situa a mulher numa posição de tomar decisões, julgar possibilidades e selecionar eventos significativos ao seu bem-estar e ao do outro.

Esse modo de ser atribui importância fundamental ao significado da vida social e pessoal ${ }^{7}$. Assim, apresentamos como objetivo deste estudo compreender o significado do planejamento familiar dado por mulheres em idade reprodutiva, identificar suas percepções sobre a assistência recebida e a participação do parceiro nas decisões do uso do método anticoncepcional.

\section{Metodologia}

Trata-se de um estudo descritivo, de natureza qualitativa, pois procuramos conhecer a subjetividade contida nas experiências das mulheres, as quais não podem ser demonstradas à operacionalização de variáveis8.

Realizamos o estudo em uma Unidade Básica de Saúde (UBS) de Fortaleza (CE), no período 
de agosto a outubro de 2007, com 24 mulheres assistidas em planejamento familiar, com semelhanças sociais, econômicas, educacionais e independentemente de raça, idade, religião ou situação marital.

A coleta de dados foi realizada por meio de entrevistas gravadas e norteadas por questões sobre o perfil sociodemográfico e de saúde e o significado do planejamento familiar, enfatizando a relação com o atendimento recebido e a participação do parceiro. Os dados foram organizados em temática, que consistiu em descobrir os núcleos de sentido de uma comunicação cuja presença ou frequência tenha significado para o objeto analítico visado ${ }^{8}$. Os depoimentos foram submetidos a três fases de organização: pré-análise, exploração do material e tratamento dos resultados.

A pré-análise caracterizou-se pela operacionalização das ideias iniciais. Após repetidas leituras, os dados foram agrupados, permitindo formular as temáticas. Na exploração do material, foi realizada uma leitura fragmentada de todo o material, com a intenção de reuni-los em unidades de significados convergentes e divergentes.

Nessa trajetória, os resultados foram organizados nas temáticas: significado do planejamento familiar dado por mulheres em idade fértil; interações de mulheres em idade fértil em um serviço de planejamento familiar; e participação masculina no planejamento conforme significado dado por mulheres. Por fim, os resultados foram tratados tomando por base a abordagem do interacionismo simbólico, inter-relacionando-os com as dimensões teóricas e interpretativas de Blumer ${ }^{7}$, mas também de outros autores que pesquisam essa temática.

O projeto foi aprovado pelo Comitê de Ética em Pesquisa da Universidade de Fortaleza, em conformidade com as diretrizes do Conselho Nacional de Saúde do Ministério da Saúde?

\section{Resultados e discussão}

As participantes do planejamento familiar tinham idade entre 13 e 36 anos, 19 eram casadas, quatro eram solteiras e tinham companheiros e uma era divorciada. As mulheres com maior número de filhos abandonaram os estudos antes de concluir o ensino fundamental. Quanto à religião, 17 eram católicas, seis evangélicas e uma era mórmon.

A renda familiar mensal variou de $\mathrm{R} \$ 50,00$ a $\mathrm{R} \$ 1.140,00$, e três mulheres não souberam informar. Em relação aos antecedentes gestacionais, 13 das respondentes afirmaram ter planejado seus filhos, 11 relataram gravidez não planejada; destas, cinco fizeram aborto. As mulheres falaram do aborto com naturalidade, dureza e coragem de enfrentá-lo e relataram a facilidade com que adquiriam os meios para fazê-lo: Eu já engravidei foi muito, já fiz três abortos, tomei remédio para abortar e não tenho vergonha de falar, não. Este depoimento foi justificado pela idade precoce, o abandono do parceiro e a necessidade de permanecer no emprego. Nesse sentido, a conceitualização do interacionismo simbólico explica que o comportamento humano envolve as experiências e significados dos indivíduos diante das crenças e do ambiente natural de cada pessoa, apresentando estreita relação entre o aspecto subjetivo do comportamento humano e a dinâmica social ${ }^{7}$.

\section{Significado do planejamento familiar dado por mulheres em idade fértil}

O PF deve ser um elemento essencial na prevenção primária de saúde, auxiliando as pessoas que procuram os serviços, oferecendo-lhes informações necessárias para a escolha e o uso efetivo dos métodos anticoncepcionais (MAC) que melhor se adaptem às condições atuais de saúde. De acordo com o Ministério da Saúde, planejamento familiar é o direito que toda pessoa tem à informação e ao acesso aos recursos que permitam optar livre e conscientemente por ter ou não ter filhos. O número, o espaçamento entre eles e a escolha do método anticoncepcional mais adequado são opções que toda mulher deve ter em relação ao direito de escolher de forma livre e por meio da informação, sem discriminação, coerção ou violência ${ }^{3}$.

Em vista desse conceito, o planejamento familiar (PF) foi expresso por algumas mulheres sob a dimensão econômica: Quanto mais filho, mais obrigação, mais despesa; enquanto outras o significaram como independência e liberdade: $E u$ acredito que seja para chegar seu filho mais ou menos na data que você quer. É importante porque eu só engravido se eu quiser.

O controle da fecundidade está relacionado a um exercício de poder da mulher sobre seu corpo, regulando seu destino biológico da procriação. Evitar filhos também foi decisão como suporte para uma vida menos sofrida e ao mesmo tempo livre de certas dificuldades vivenciadas na família e na sociedade: Para não ter filhos indesejados, não prejudicar a vida. A pessoa vive no mundo que nós vivemos [referindo-se às dificuldades econô- 
micas, à violência], a dificuldade está aí para todo mundo ver, as pessoas não se previnem, não buscam uma vida melhor. Eé porque hoje em dia essas meninas sabem de tudo. Eu tenho prima que teve menino com 15 anos e já tem um monte de filho.

Aqui, o PF foi significado como uma ponte para uma vida melhor, ou seja, de se evitarem as gestações indesejadas e de ter filhos conforme as condições econômicas. Esse mesmo sentimento foi manifestado por mulheres também cearenses participantes de outro estudo ${ }^{5}$, as quais afirmaram que o PF ajuda a evitar o "sofrimento" causado pelas necessidades básicas insatisfeitas, principalmente relacionado à falta de alimentação na família.

As experiências foram relevantes para a compreensão dos significados que as mulheres atribuíram ao planejamento familiar, permeados por fatores do contexto social em que se inserem. Neste sentido, o significado resulta da interação que cada mulher mantém com as pessoas e com o meio no qual ela vive ${ }^{7}$.

A maioria das mulheres associou o planejamento familiar apenas ao uso de anticoncepcional oral e do preservativo masculino. Esse panorama evidencia a precariedade da atenção dada à mulher e as poucas opções dos métodos anticoncepcionais, com negação de um espaço para escolhas reprodutivas livres e informadas.

A precariedade de informações, conhecimentos e saberes foi constatada nas falas de dez mulheres que, com timidez e limitações, expressaram ideias como a seguinte: É uma consulta que a gente faz todo mês, para pegar comprimido e camisinha.

Desse modo, torna-se perceptível o descompasso entre o que está proposto na política de planejamento familiar e o que, efetivamente, está implementado. A informação adequada provoca um impacto na mulher, levando-a a formar as próprias opiniões e tomar decisões quanto ao futuro de sua família.

Duas participantes evidenciaram a importância do planejamento familiar nos seguintes termos: Isso eu sei, sim, a enfermeira me explicou, disse que é um acompanhamento que a gente faz no posto de saúde para não engravidar sem querer e para não pegar doenças também. Mas eu não sabia que tinha esse nome, pensava que fosse mesmo só pegar o remédio e que esse tal de planejamento familiar fosse outra consulta. Agora eu sei que pegar remédio e camisinha faz parte do planejamento familiar. Eu ensinei até para o meu esposo, porque ele também não sabia, não.

Esse recorte é uma amostra de que, havendo empenho em informar a clientela, possibilita a esta a participação e a corresponsabilidade nas suas metas reprodutivas. Portanto, reconhecemos a importância da informação para uma prática consciente, saudável e efetiva da clientela, como medida de promoção da saúde e para diminuir a distância entre o que é dito e o que é feito.

Informações passadas às mulheres são captadas por parte destas e, muitas vezes, parcialmente, seja pela dificuldade de compreensão atrelada à baixa escolaridade, ao baixo interesse ou oportunidade de convívio e interação social sobre a temática serem escassas e conduzidas por técnicas de comunicação inadequadas. Torna-se necessário, pois, refletir sobre como essas informações são dadas e recebidas pelas mulheres, como estas apreendem e a utilizam em prol da sua saúde sexual e reprodutiva.

Outras dez mulheres manifestaram pleno desconhecimento sobre o termo: Ih... Me pegou! Planejamento familiar? Sei não, esse nome aí nunca ouvi falar, não, e se ouvi não lembro o que é. É preciso convocar a equipe de saúde para o compromisso de gerar oportunidades para que as pessoas desenvolvam o senso de corresponsabilidade, tanto por sua própria saúde quanto pela saúde da comunidade, mudando os comportamentos sociais, políticos e culturais ${ }^{5}$.

Para tanto, as ações educativas em saúde são processos que objetivam capacitar indivíduos ou grupos, de modo que possam assumir ou ajudar na melhoria das condições de saúde da população. Para a realização dessas atividades, são necessários profissionais capacitados, estrutura física e, principalmente, a participação das mulheres.

No entanto, alguns profissionais, mesmo com a inexistência de área física adequada para o desenvolvimento de atividades de orientação/informação em saúde, improvisavam atividade grupal antes da realização da consulta de PF. Nessas atividades, as mulheres demonstravamse tímidas e apressadas, querendo tão somente receber o anticoncepcional, o que foi confirmado pelas enfermeiras da unidade, que relataram dificuldade de adesão de parte das mulheres em reuniões previamente marcadas, dificultando ações grupais que possivelmente atendessem a várias carências de informações.

Parte dos profissionais considera que as pessoas se inibem e não comparecem a palestras exclusivamente sobre planejamento familiar, sendo mais fácil abordar o assunto no âmbito de outros grupos educativos já existentes ${ }^{10}$. Talvez a dinâmica de como essas atividades venham se dando esteja deslocada da realidade da população, como relata Freire ${ }^{11}$ : é muito difícil aprender 
e reter conhecimentos quando a preocupação maior é a sobrevivência e os educadores falam de coisas como Eva e as uvas, existindo homens que sabem muito pouco de Eva e nunca comeram uvas.

Para contornar tal situação, o Ministério da Saúde ressalta que é de fundamental importância às práticas educativas terem um caráter participativo, permitindo a troca de informações e experiências com base nas vivências de cada indivíduo. Assinala, ainda, que a linguagem utilizada pelo profissional de saúde deva ser acessível, simples e precisa ${ }^{3}$.

\section{Interações de mulheres em idade fértil em um serviço de planejamento familiar}

O serviço próximo de onde as pessoas vivem favorece o vínculo das usuárias, facilita o recebimento do método e, consequentemente, o uso mais sistemático. O Ministério da Saúde propõe distribuir a rede de serviços de forma planejada, levando em conta a localização geográfica da UBS, e expressa ainda que o serviço deve ser regionalizado, com as unidades distribuídas espacialmente na proximidade do local de trabalho e moradia, levando-se em conta as condições de transpor$\mathrm{te}^{12}$. Nesse sentido, a escolha da unidade de saúde contemplou a seguinte declaração de todas as usuárias: Porque é o mais perto da minha casa.

Na UBS estudada, o enfermeiro assume a maior parte do atendimento em PF, encaminhando a cliente ao atendimento médico quando identifica alguma alteração ou esta solicita a troca do MAC. É preciso uma política nacional de planejamento familiar que reconheça o potencial do enfermeiro em manejar os métodos anticoncepcionais e explicite seu amparo legal, para que este assuma com autonomia essa área do cuidado para a qual soma grande contribuição ${ }^{6}$.

Embora as atividades de planejamento sejam desenvolvidas por enfermeiros, o Ministério da Saúde preconiza que a atuação dos profissionais na assistência à anticoncepção deva promover a interação dos membros da equipe de saúde, de forma que permita a participação dos diversos elementos nas atividades, de acordo com a responsabilidade requerida em cada situação ${ }^{3}$.

Os depoimentos que seguem são traços da dinâmica do serviço, expressos como mais significativos para as mulheres: Tem dia que eu sou bem recebida e tem dia que não, depende da pessoa. No consultório a gente geralmente é bem atendida, todos eles são maravilhosos. Mas lá fora, quando a gente chega, os atendentes recebem mal, por eles acharem que posto é público. Eu não sei se é devido à quantidade de pessoas que elas ficam um pouco estressadas, eu não sei. Não dão a informação direito, é uma complicação medonha, um não sabe, outro não sabe, fica passando pra outro, tem muita confusão na fila, mas também quando consegue ébom.

$\mathrm{O}$ atendimento oferecido produz descontentamento nas usuárias, que relataram falta de informação e de organização no atendimento inicial, desde a chegada à marcação e confirmação da consulta. Vale ressaltar que essas mulheres procuravam a UBS pelo menos uma vez ao mês para o serviço de planejamento familiar, indo mais vezes para outros serviços, algo desnecessário e que precisa ser corrigido.

$\mathrm{O}$ atendimento dos profissionais é elogiado, confirmando a grande contribuição, especialmente do enfermeiro nessa área do cuidado, assumindo seu papel de orientador, educador e conselheiro.

Durante as entrevistas, 14 das participantes relataram receber informações dos profissionais em relação ao planejamento familiar: Para mim não falta informação. A enfermeira é jóia, tem paciência e responde tudo que eu pergunto, mas eu já ouvi dizer que nem todas aqui são assim não, viu? Por isso que eu não troco esse meu horário.

Outras dez respondentes, porém, referiram falta de informação: Acho que falta, sim. Elas falam só que não pode parar de tomar o remédio porque se não engravida, mas às vezes quero perguntar e fico com vergonha, só pergunto quando é o jeito, mesmo! Geralmente prefiro perguntar para minha irmã.

Algumas participantes relataram que o problema não é a falta de informação, e sim a maneira como o profissional passa essa informação: Não é bem falta de informação; acho que alguns doutores aqui deveriam ter mais paciência na hora de explicar as coisas para a gente, porque às vezes a gente não entende tudo. Este depoimento leva a refletir sobre até que ponto os profissionais de saúde estão preparados para trabalhar esse aspecto de dar informação.

Outro ponto crítico das ações educativas em planejamento familiar refere-se à necessária compatibilidade entre informação e disponibilidade de tecnologia contraceptiva. Para que a escolha da pessoa possa ser livre, é necessário que esta tenha acesso a qualquer um dos métodos sobre os quais recebeu informação. A UBS dispunha de preservativo masculino, anticoncepcional oral, minipílula, dispositivo intrauterino (DIU) e anticoncepcional injetável. Houve, no entanto, dis- 
cordância com a população pesquisada: Eu nem sei dizer direito, porque aqui no posto só tem comprimido, camisinha e DIU. Camisinha meu marido não gosta, DIU é difícil que só para conseguir; só sobra mesmo o comprimido, é melhor que não usar nada, porque se eu quiser tomar a injeção vou ter que comprar.

Identificamos que a limitação de recursos financeiros determina a escolha do MAC utilizado pelas mulheres, que é satisfatório quando usado o anticoncepcional oral e/ou preservativo masculino, pois, segundo elas, é mais difícil faltar na UBS. Portanto, o uso desses MAC é por falta de opções e condição econômica desfavorável, o que corrobora o estudo de Carreno ${ }^{13}$, o qual revelou prevalência da anticoncepção oral nas mulheres de classes de menor inserção econômica, por ser a única opção ao alcance.

Para o interacionismo simbólico, o ser humano tem uma composição que combina natureza e interação social, e é visto como um ser que age, sendo objeto de sua ação. Chamou a nossa atenção o fato de que 19 mulheres tiveram uma livre escolha do método: Eu queria usar alguma coisa para não engravidar e procurei o posto para pegar comprimido. Fui eu que escolhi.

$\mathrm{Na}$ prática assistencial, as mulheres, quando pretendem usar um método específico, chegam aos serviços de saúde com a decisão tomada e não se mostram receptivas a uma orientação ampla, completa, acerca de todas as opções dos métodos anticoncepcionais disponíveis ${ }^{14}$. $\mathrm{E}$ isto decorre do conhecimento informal adquirido por elas ao longo das experiências de vida, além da troca de informações com parentas e amigos.

Nas entrevistas, seis mulheres relataram que houve influência dos profissionais de saúde na escolha do MAC e enfatizaram a enfermeira como um ponto forte na realização do planejamento familiar: Eu que vim fazer prevenção uma vez e perguntei para a enfermeira como era para pegar o remédio para não engravidar e ela me disse e eu comecei a usar.

O ser humano recebe influência do meio cultural em que está inserido em consequência do processo acumulativo das experiências vividas. A interação simbólica está diretamente ligada à comunicação; quando as mulheres definem significados, estão simplesmente reagindo a estímulos sociais que tiveram, os quais têm sentido pela interação enfermeiro-mulher.
Participação masculina no planejamento familiar conforme o significado feminino

Neste estudo, o envolvimento dos homens no planejamento da família e na vida sexual foi muito restrito. Será que essa atitude é inerente ao fato de ser, por natureza, a mulher que engravida? Será que o homem percebe o significado de sua participação no planejamento familiar? Os empecilhos práticos não justificam o papel limitado que os homens desempenham na concepção, contracepção e sexualidade do casal, pois as mulheres também praticam uma variedade de atividades domésticas, familiares e profissionais.

Para comprovar a ausência dos homens junto às mulheres nesse plano de vida, registramos em todos os depoimentos o quanto a mulher decide, confia e assume sozinha: Não, ele não tem participação em nada. Não reclama, para ele tanto faz. Eu que resolvo tudo só, ele não fala nem nesse assunto, só quer saber se eu não estou grávida, na cabeça dele só o que importa é isso.

Durante o período do estudo, não conseguimos entrevistar homens no serviço de PF e também não observamos sua presença em nenhum momento. Embora estejamos diante de um novo modelo de papéis sociais na família, muitos homens ainda permanecem segregados do universo feminino.

Partindo da premissa de que a concepção é um resultado natural e sexual entre homem e mulher, espera-se que a anticoncepção seja um fenômeno resultante da conjugação de esforços dos parceiros igualmente envolvidos nessa relação. Não foi, entretanto, esse o resultado encontrado, pois a cultura masculina predomina sobre a feminina, enfatizando a responsabilidade da mulher no âmbito do planejamento familiar.

No contexto internacional, a Conferência de Beijing, promovida pela Organização das Nações Unidas em 1995, alerta para a importância da divisão da responsabilidade pela anticoncepção entre ambos os sexos, visando à promoção da saúde reprodutiva, e enfatiza a sua relevância para a consolidação de uma sociedade democrática e para o desenvolvimento da cidadania ${ }^{15}$. Essa divisão de responsabilidades, todavia, não foi observada neste estudo, tendo sido confirmado pelas mulheres o fato de que não há participação efetiva de seus companheiros no planejamento familiar: Ele se constrange... Seria bom ele vir, mas 
a gente não tem essa orientação e acha que é consulta nossa e tem que ir só. Seria bom, pra ele ficar a par da situação, o que ela fala pra mim ele entender também.

Algumas mulheres pretendiam uma participação mais ativa do companheiro e assim dividir a responsabilidade da anticoncepção; relataram que não sabiam da existência do PF com os homens, pois falta "essa orientação".

Numa reflexão sobre a participação do parceiro, verificamos que praticamente inexistem esses serviços dirigidos à clientela masculina nos serviços públicos, com horários adequados, desvinculados dos serviços de ginecologia, e que além de informação adequada sobre contracepção, provisão de preservativos e oferta de vasectomia, tratem de questões que abarquem a sexualidade e a prevenção de doenças sexualmente transmitidas ${ }^{16}$.

A UBS em estudo funciona em três turnos diários, portanto, enseja a presença do homem no serviço, caso este disponibilize seu tempo junto à parceira ou sozinho para receber orientações, informações para a realização do planejamento familiar.

Outros cinco parceiros, além de não participar, querem mais filhos: Ele é doido para eu deixar esse comprimido de mão e engravidar.

Está explicitado, nesses casos, o fato de que, quando não há consenso sobre o tamanho da prole, por meio do uso de métodos que prescindem da participação masculina, a mulher poderia manter o controle sobre a sua própria fecundidade. Um exercício de autonomia? De cidadania?

As relações entre homens e mulheres refletem os padrões culturais de uma sociedade, pois a mulher, conquistando um espaço cada vez maior, entra no mercado de trabalho e assume a corresponsabilidade ou até a responsabilidade no sustento da família. A divisão das tarefas na família, porém, ainda não é tão comum ${ }^{17}$.

O cuidado dos filhos e o controle da fecundidade ainda são considerados, pela sociedade e até pelas próprias mulheres, como uma função feminina, e três mulheres excluíam o homem da responsabilidade de contracepção: Não queria que ele participasse. Ele não vem, ele não gosta, até quando ele está doente ele não vem no posto. Fica em casa. E eu prefiro vir só, já tenho costume.

Essas mulheres mostraram-se tímidas e preferiam que o parceiro continuasse com um papel passivo na anticoncepção, em virtude da cultura; preferiam que ele ficasse em casa e elas se responsabilizassem pela escolha e o uso continuado do método. Nesse caso, talvez em mais uma arma- dilha de gênero, ao assumir sozinha a contracepção, a mulher estaria liberando o homem das tarefas do mundo privado, da família.

Verificamos que a forma de participação masculina em anticoncepção é mínima, e as mulheres se davam por satisfeitas diante da aceitação do uso do preservativo; esta foi a maneira mais ativa que encontramos em relação ao companheiro: Eu pedi para ele usar e ele aceitou, porque tem uns que não querem usar de jeito algum, mas o meu esposo sempre conversa comigo. Só esse último filho que a gente não se programou, mas os outros a gente quis engravidar.

Ainda que alguns autores enfatizem a importância dessa participação no planejamento familiar e na anticoncepção de maneira geral, a responsabilidade recai quase exclusivamente sobre a mulher.

Um dos mais antigos métodos contraceptivos de uso masculino é o preservativo, e sua aceitabilidade entre os homens ainda é pequena, porém negociável. São as mulheres que procuram os serviços de saúde para recebê-lo. Elas relataram, com grande ênfase, a não aceitação pelos homens. Os seguintes trechos revelam: É meio difícil, praticamente eu que decido, porque meu marido nem vem comigo para a consulta, nem quer usar camisinha, e por isso sobra só o comprimido para eu tomar e pronto.

O que determina o quê? A escolha do método feminino de alta eficácia dispensa o homem da responsabilidade, ou a falta de envolvimento masculino determina a escolha do método? Com base nas respostas obtidas, não foi possível esclarecer essa relação.

A não aceitação do uso do preservativo é visto pela mulher como uma atitude do homem de não participar e colaborar na contracepção. Observamos que as mulheres negociavam em algumas situações, revelando seus desejos e necessidades. Em contrapartida, com um estudo realizado, as mulheres tinham sentimento de opressão, autoridade, poder e domínio do homem e se revelaram carentes de solidariedade ${ }^{18}$.

A análise desses dados nos possibilitou observar baixa aceitabilidade masculina ao preservativo, e os motivos nem sempre são bem explicitados. Outro estudo assinalou a diferença entre as extensas argumentações e justificativas apresentadas quando a mulher rejeita um método, como se, no caso dela, isso fosse necessário, enquanto no caso do homem o argumento "ele não gosta" parece ser suficiente ${ }^{19}$. Pode estar implícita a falta de poder de negociação da mulher, que prefere usar algum método feminino, mesmo 
sofrendo efeitos colaterais, do que argumentar com seu parceiro sobre o uso do preservativo.

Um dado muito particular foi observado em uma participante que não usava preservativo com seu parceiro, mas recebia o insumo na UBS para entregá-lo e lembrava: Às vezes ele usa comigo. E eu ainda dou para ele, e eu digo: se você for com outra mulher você use, não traga doença para casa, não. Os valores morais mudaram no decorrer dos tempos, e encontra-se a mulher mais preocupada em não contrair uma doença sexualmente transmissível (DST) e não com a fidelidade do parceiro.

Constatamos em outro depoimento o uso do preservativo e contraceptivo oral após uma gravidez não planejada e seguida de um aborto: No início ele não gostava de camisinha, mas depois que tive uma gravidez indesejada e provoquei o aborto, aí ele já se conformou.

Portanto, é uma dinâmica que não exclui as mulheres que não tiveram experiências positivas. Dependendo do meio cultural em que ela está inserida, nas experiências com as quais se deparam no decorrer da vida o estímulo recebido pode superar os fatores negativos. Esse depoimento evidencia o fato de que os atos humanos não são meramente repetições de situações vividas no passado, e sim são assimilados e vão adquirindo significado para as pessoas envolvidas.

\section{Considerações finais}

O significado do planejamento familiar para as mulheres do estudo mostrou-se relacionado com valores pertinentes às suas realidades cultural, econômica e social; portanto, o significado desse programa está atrelado aos símbolos expressados por elas em algum momento da sua vivência.

As mulheres do estudo demonstraram ter autonomia e liberdade para decidir sobre a gravidez e o método contraceptivo utilizado. Acentuaram com veemência que as dificuldades financeiras e o sofrimento estão relacionados ao número de filhos e às condições de vida no âmbito social e instrucional.

A assistência ao planejamento familiar está distante de um patamar satisfatório, pois as ações são executadas de forma isolada e não priorizadas como os demais componentes da atenção básica. As orientações individuais podem ser uma oportunidade indiscutível para se estabelecer um adequado processo de interação para a formulação dos significados, mas têm limitado poder de alcance, em razão de falta de entendimento de algumas mulheres, necessitando de ações mais concretas, objetivas e realizadas de forma individualizada ou em pequenos grupos.

É preciso realizar ações que vão além da UBS, com investimentos na educação, possibilitando a capacitação das mulheres para transformar o significado a partir das informações e não somente no sentido da escolaridade formal, mas também de torná-la capaz de identificar suas necessidades e lutar por seus direitos, entre os quais os insumos necessários para a anticoncepção.

Evidenciamos nas respostas o fato de que a proximidade da UBS favoreceu a escolha do local, como é preconizado pelo Ministério da Saúde. Outro aspecto importante identificado foi a insatisfação das usuárias com a receptividade e o acolhimento durante a marcação da consulta. Em contrapartida, foi enfatizada a qualidade do atendimento durante a consulta de enfermagem, que era acolhedora e humanizada, permitindo que a usuária interagisse com o profissional.

Para as mulheres, a limitação financeira e a falta de opção dos MACs foram fatores determinantes da aceitação destes, sendo distribuídos, mais amplamente, o anticoncepcional oral e o preservativo masculino, embora este último tivesse baixa aceitabilidade pelos homens. Observamos ainda a passividade masculina na contracepção, impondo o poder de decisão da mulher, impedindo que as responsabilidades sejam partilhadas.

Sugerimos que ações de planejamento familiar ultrapassem o simples ato da entrega de anticoncepcionais e promovam relações familiares, comunitárias e sociais mais saudáveis, com espaços para todos conversarem e trocarem experiências sobre as condições de vida, visando a uma participação ativa do parceiro e de todos os membros da equipe de saúde. Reconhecemos a importância da qualidade desse serviço para as mulheres e casais, a fim de que possam ter uma prática saudável e efetiva como medida de promoção da saúde. 


\section{Colaboradores}

RM Silva trabalhou na concepção do projeto, interpretação dos dados, redação do artigo e revisão crítica; KNC Araújo, na concepção do projeto, coleta de dados, interpretação dos dados e redação final do artigo; LAC Bastos, na coleta de dados, interpretação dos dados e redação; ERF Moura, na revisão crítica, interpretação dos dados e redação do artigo.

\section{Referências}

1. Ávila MB, Corrêa S. Movimento de saúde e direitos reprodutivos no Brasil: revisitando percursos - saúde sexual reprodutiva no Brasil. São Paulo: Hucitec; 1999.

2. Tyrrel MA, Carvalho V. Programas nacionais de saúde materno-infantil: impacto político social e inserção de enfermagem. Rio de Janeiro: Editora da UFRJ; 1995.

3. Brasil. Ministério da Saúde. Assistência em planejamento familiar: manual técnico. Brasília: Ministério da Saúde; 2002.

4. Brasil. Ministério da Saúde. Política Nacional de Atenção Integral à Saúde da Mulher: plano de ação 20042007. Brasília: Ministério da Saúde; 2004.

5. Moura ERF, Silva RM. Informação e planejamento familiar como medidas de promoção da saúde. Cien Saude Colet 2004; 9(4):1023-1032.

6. Moura ERF, Silva RM, Galvão MTG. Dinâmica do atendimento em planejamento familiar no Programa Saúde da Família no Brasil. Cad Saude Publica 2007; 23(4):961-970.

7. Blumer H. Symbolic interactionism: perspective and method. Berkeley, Califórnia: Prentice-Hall; 1969.

8. Minayo MCS. O desafio do conhecimento: pesquisa qualitativa em saúde. 9a ed. São Paulo: Hucitec; 2006.

9. Brasil. Conselho Nacional de Saúde. Normas para pesquisa envolvendo seres humanos. Brasília: Ministério da Saúde, Comissão Nacional de Ética em Pesquisa; 2000. p. 22-23.

10. Osis MJD, Faúndes A, Makuch MY, Mello MB, Sousa MHS, Araújo MJO. Atenção ao planejamento familiar no Brasil hoje: reflexões sobre os resultados de uma pesquisa. Cad Saude Publica 2006; 22(11):24812490.

11. Freire P. Conscientização: teoria e prática da libertação, uma introdução ao pensamento de PF. São Paulo: Moraes; 1980.

12. Brasil. Ministério da Saúde. Modelos assistenciais no SUS. Brasília: Ministério da Saúde; 1990.

13. Carreno I, Dias da Costa JS, Olinto MTA, Meneghel S. Uso de métodos contraceptivos entre mulheres com vida sexual ativa em São Leopoldo, Rio Grande do Sul, Brasil. Cad Saude Publica 2006; 22(5):1101-1109.

14. Marchi NM. Vasectomia: razões da opção de casais pelo método [dissertação]. São Paulo: Faculdade de Saúde Pública da Universidade de São Paulo; 2001.

15. Piovesan F, Pirotta WRB. A proteção dos direitos reprodutivos no direito internacional e no direito interno. In: Piovesan F. Temas de direitos humanos. São Paulo: Max Limonad; 1998. p. 166-202. 
16. Population Reference Bureau. Inquietudes femininas: las mujeres escriben sobre la participación de los hombres en la familia. Washington (DC): PRB; 1995.

17. Carvalho MLO, Pirotta KCM, Schor N. Participação masculina na contracepção pela ótica feminina. Rev Saude Publica 2001; 35(1):23-31.

18. Marcolino C, Galastro EP. As visões feminina e masculina acerca da participação de mulheres e homens no planejamento familiar. Rev Lat-Am Enfermagem 2001; 9(3):77-82.

19. Carvalho MLO, Schor N. Motivos de rejeição aos métodos contraceptivos reversíveis em mulheres esterilizadas. Rev Saude Publica 2005; 39(5):788-794.

Artigo apresentado em 29/01/2008

Aprovado em 31/07/2008

Versão final apresentada em 23/08/2008 